\title{
Risk factors for epistaxis in patients followed in general practices in Germany*
}

\author{
David Ulrich Seidel', Louis Jacob², Karel Kostev³, Andreas M. Sesterhenn' \\ 'Department of Otorhinolaryngology, Head and Neck Surgery, Solingen Municipal Hospital, Solingen, Germany \\ 2 Faculty of Medicine, University of Paris 5, Paris, France \\ Epidemiology, QuintilesIMS, Frankfurt, Germany
}

Rhinology 55: 312-318, 2017

https://doi.org/10.4193/Rhino17.105

*Received for publication:

May 22, 2017

Accepted: June 19, 2017

\begin{abstract}
Background: The goal of the present study was to analyze the risk factors for epistaxis in patients followed in general practices in Germany.

Methods: The current study sample included patients aged 18 years or older who received a first epistaxis diagnosis between January 2012 and December 2016 (index date). Epistaxis patients and controls without epistaxis were matched (1:1) on the basis of age, gender, insurance status and physician.

Results: A total of 16,801 patients with epistaxis and 16,801 control subjects were included in this study. Of the subjects, $53.2 \%$ were men, and the mean age was 59.6 years ( $S D=21.2$ years). Epistaxis was found to be positively associated with hypertension, obesity, chronic sinusitis, other disorders of the nose and nasal sinuses, anxiety disorder, and adjustment disorder (ORs ranging from 1.13 to 1.44). Epistaxis was also associated with the prescription of vitamin K antagonists, preparations from the heparin group, platelet aggregation inhibitors excluding heparin, direct thrombin inhibitors, direct factor Xa inhibitors, other antithrombotic agents, selective serotonin reuptake inhibitors and nasal steroids (ORs ranging from 1.15 to 3.55 ).
\end{abstract}

Conclusions: Overall, epistaxis risk is increased by multiple medical and psychiatric disorders. Several antithrombotic and nasal steroid therapies are also associated with this risk.

Key words: epistaxis; risk factors; general practices

\section{Introduction}

Epistaxis is a rhinologic symptom that accounts for a substantial share of visits to general practices, ENT practices, and emergency departments ${ }^{(1)}$. A 2005 U.S. study showed that epistaxis accounts for 450,000 emergency department visits per year $(0.46 \% \text { of all ED visits })^{(2)}$. The age-related frequency is bimodal, with a first peak in children younger than 10 years old, and a second peak in the elderly aged between 70 and 79 years old (2). The majority of epistaxis cases are atraumatic, and only $6 \%$ of them require prolonged hospitalization. Nonetheless, the cost per patient of epistaxis-related hospitalizations is around $\$ 7,000$, thus emphasizing the major impact that this condition has on health and the economy in Western countries ${ }^{(3-5)}$.

Several authors have focused on the factors that potentially in- crease the risk of being diagnosed with epistaxis. In 2000, Herkner et al. found that mean blood pressure values were higher in 213 emergency department patients affected by epistaxis than in 213 controls, and that $79 \%$ of the followed 33 patients had sustained arterial hypertension ${ }^{(6)}$. In contrast, in 2009, Knopfholz and colleagues showed no association between hypertension severity and epistaxis episode incidence in 36 hypertensive patients with epistaxis in a prospective study design ${ }^{(7)}$. In 2010, Soyka et al. showed in a prospective study that acetylsalicylic acid (ASA) intake is a major risk factor for epistaxis, with ASA being prescribed to almost $30 \%$ of the 591 epistaxis patients ${ }^{(8)}$. In the same study, individuals with ASA intake were more likely to have recurrent bleeding and to require surgical intervention to control the bleeding than those without ASA intake. A more 
recent retrospective cohort study of 20 years (1991-2011) compared 461 patients affected by recurrent epistaxis ( $>1$ episode) with 912 controls with only 1 episode, and detected that congestive heart failure, diabetes mellitus, hypertension, a history of anemia, and warfarin intake, but not ASA or clopidogrel intake, were risk factors for recurrent episodes of spontaneous epistaxis (1). Finally, in 2016, Stadler and colleagues found in a combined retrospective and prospective cohort study that the intake of vitamin $\mathrm{K}$ antagonists increases the risk of recurrence of epistaxis episodes with an odds ratio of 11.6 and that ASA intake increases the necessity for surgical intervention ${ }^{(9)}$.

The aforementioned studies were carried out in tertiary care centers (emergency departments and ENT departments) using relatively small numbers of patients. Risk factors for epistaxis in patients followed by primary care providers have not been described yet. The aim of the present study was to analyze the risk factors for epistaxis in a large number of patients followed in general practices in Germany.

\section{Materials and methods}

\section{Database}

The present study is based on data from the Disease Analyzer database (QuintilesIMS), which compiles drug prescriptions, diagnoses, and basic medical and demographic data obtained directly and in anonymous format from computer systems used in physicians' practices ${ }^{(10)}$. Diagnoses (ICD-10), prescriptions (Anatomical Therapeutic Chemical [ATC] Classification System), and the quality of reported data are monitored by QuintilesIMS based on a number of criteria (e.g., completeness of documentation and linkage between diagnoses and prescriptions).

The sampling method for the Disease Analyzer database is based on summary statistics from all physicians in Germany published annually by the German Medical Association (Bundesärztekammer) [http://www.baek.de]. These statistics are used to determine the panel design according to the following strata: specialist group, German federal state, community size category, and age of physician, in order to obtain a representative database of physicians ${ }^{(10)}$.

\section{Study population}

The current study sample included patients aged 18 years or older who received a first epistaxis diagnosis (ICD 10: R04.0) from 1,262 German general practitioners between January 2012 and December 2016 (index date). Patients with a follow-up time of less than 365 days prior to the index date were excluded. After applying identical inclusion criteria, epistaxis patients and controls without epistaxis were matched (1:1) based on age, gender, insurance status, and physician (Figure 1).

\section{Independent variables}

Demographic data included age, gender, and health insurance

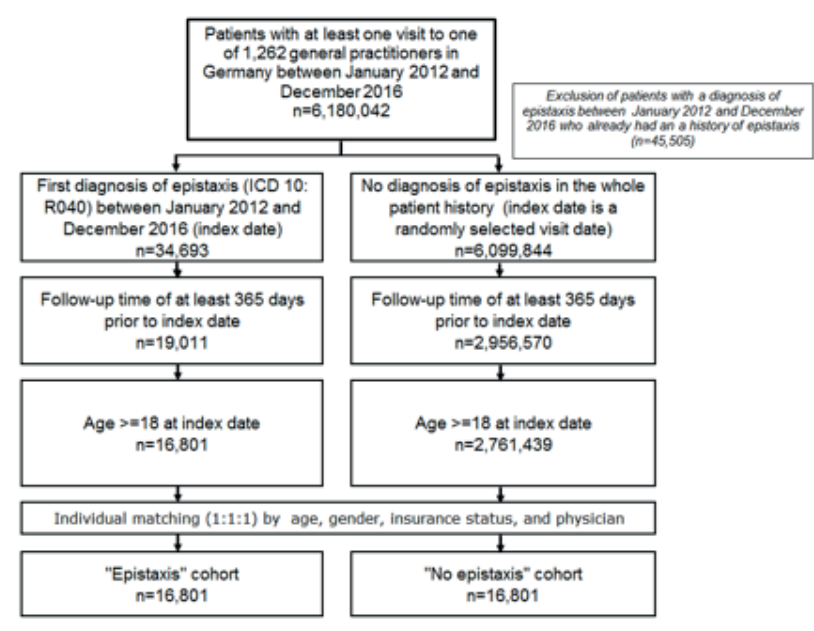

Figure 1. Selection of study patients.

type (private or statutory). Clinical data included diagnoses documented within 365 days prior to the index date (ICD-10 codes): hypertension (I10), obesity (E66), coronary heart disease (I20-I25), heart failure (I10), subarachnoid, intracerebral or other non-traumatic intracranial hemorrhage (160-62), Osler's disease (I78.0), diabetes (E10-E14), allergic rhinitis (J30), chronic sinusitis (J32), nasal polyp (J33), fracture of nasal bones (S02.2), other disorders of nose and nasal sinuses (including cyst and mucocele of nose and nasal sinus, deviated nasal septum, hypertrophy of nasal turbinates, abscess, furuncle, and carbuncle of nose; J34), depression (F32, F33), anxiety disorder (F41), and adjustment disorder (F43). Finally, the following families of drugs documented within 365 days prior to the index date were available for the analysis (ATC classification system): vitamin $\mathrm{K}$ antagonists $(B 01 A A)$, heparins $(B 01 A B)$, platelet aggregation inhibitors excluding heparin (B01AC), direct thrombin inhibitors (B01AE), direct factor Xa inhibitors (B01AF), other antithrombotic agents $(B 01 A X)$, selective serotonin reuptake inhibitors (SSRI, N06AB) and nasal steroids (R01AD).

\section{Statistical analyses}

Descriptive analyses were obtained for demographic, clinical, and pharmaceutical variables. Mean \pm SD were calculated for age, while proportions were calculated for other variables. A logistic regression model was used to calculate the association between epistaxis and the different variables. P-values $<0.05$ were considered statistically significant. Analyses were carried out using SAS version 9.3.

\section{Results}

Patient characteristics are illustrated in Table 1. A total of 16,801 patients with epistaxis and 16,801 control subjects were included in this study. Among the subjects, 53.2\% were men, and the mean age was 59.6 years ( $S D=21.2$ years). Finally, $7.2 \%$ of people 
Table 1. Characteristics of epistaxis patients and controls in general practices (QuintilesIMS Disease Analyzer database).

\begin{tabular}{|c|c|c|c|}
\hline Variable & Epistaxis & $\begin{array}{l}\text { No } \\
\text { epistaxis }\end{array}$ & p-value \\
\hline \multicolumn{4}{|l|}{ Prior to $1: 1$ matching } \\
\hline $\mathrm{N}$ & 16,801 & $2,761,439$ & \\
\hline Age (Mean, SD) & $59.6(21.2)$ & $52.7(19.2)$ & $<0.001$ \\
\hline$\leq 40$ years $(\%)$ & 21.4 & 29.0 & $<0.001$ \\
\hline $41-50$ years (\%) & 9.3 & 17.3 & $<0.001$ \\
\hline $51-60$ years $(\%)$ & 13.9 & 17.9 & $<0.001$ \\
\hline $61-70$ years $(\%)$ & 15.2 & 13.7 & $<0.001$ \\
\hline$>70$ years $(\%)$ & 40.3 & 22.1 & $<0.001$ \\
\hline Women (\%) & 46.8 & 53.8 & $<0.001$ \\
\hline Men (\%) & 53.2 & 46.2 & $<0.001$ \\
\hline $\begin{array}{l}\text { Private health insurance cover- } \\
\text { age }(\%)\end{array}$ & 7.2 & 9.5 & $<0.001$ \\
\hline $\begin{array}{l}\text { Statutory health insurance } \\
\text { coverage }(\%)\end{array}$ & 92.8 & 90.5 & $<0.001$ \\
\hline \multicolumn{4}{|l|}{ After 1:1 matching* } \\
\hline $\mathrm{N}$ & 16,801 & 16,801 & \\
\hline Age (Mean, SD) & $59.6(21.2)$ & $59.6(21.2)$ & 1.000 \\
\hline$\leq 40$ years $(\%)$ & 21.4 & 21.4 & 1.000 \\
\hline 41-50 years (\%) & 9.3 & 9.3 & 1.000 \\
\hline $51-60$ years $(\%)$ & 13.9 & 13.9 & 1.000 \\
\hline $61-70$ years (\%) & 15.2 & 15.2 & 1.000 \\
\hline$>70$ years (\%) & 40.3 & 40.3 & 1.000 \\
\hline Women (\%) & 46.8 & 46.8 & 1.000 \\
\hline Men (\%) & 53.2 & 53.2 & 1.000 \\
\hline $\begin{array}{l}\text { Private health insurance cover- } \\
\text { age }(\%)\end{array}$ & 7.2 & 7.2 & 1.000 \\
\hline $\begin{array}{l}\text { Statutory health insurance } \\
\text { coverage (\%) }\end{array}$ & 92.8 & 92.8 & 1.000 \\
\hline
\end{tabular}

* 1:1 matching by age, gender, health insurance coverage, and physician.

had private health insurance coverage. Results of the multivariate regression model are displayed in Table 2. Epistaxis was found to be positively associated with hypertension $(O R=1.13)$, obesity $(O R=1.24)$, chronic sinusitis $(O R=1.20)$, other disorders of nose and nasal sinuses ( $O R=1.44)$, anxiety disorder ( $O R=1.23)$, and adjustment disorder ( $\mathrm{OR}=1.19)$. Epistaxis was also associated with the prescription of vitamin $\mathrm{K}$ antagonists ( $\mathrm{OR}=3.55)$, preparations from the heparin group $(\mathrm{OR}=1.15)$, platelet aggregation inhibitors excluding heparin $(\mathrm{OR}=2.02)$, direct thrombin inhibitors $(O R=2.16)$, direct factor Xa inhibitors $(O R=3.36)$, other antithrombotic agents ( $O R=1.65)$, SSRIs ( $O R=1.26)$ and nasal steroids ( $\mathrm{OR}=2.24)$. No significant effect was found for coronary heart disease, diabetes, heart failure, subarachnoid, intracerebral or other non-traumatic intracranial hemorrhage, depression, Osler's disease, allergic rhinitis, nasal polyp, or fracture of nasal bones.

\section{Discussion}

In the present study, which included more than 33,600 patients followed in general practices in Germany, epistaxis was positively associated with hypertension, obesity, chronic sinusitis, other disorders of nose and nasal sinuses, depression, anxiety disorder, and adjustment disorder. It was also reported that the likelihood of developing epistaxis was increased by the use of vitamin $\mathrm{K}$ antagonists, heparins, platelet aggregation inhibitors, direct thrombin inhibitors, direct factor Xa inhibitors, other antithrombotic agents, SSRIs and nasal steroids.

Over the past decades, several authors have studied the impact of medical conditions and prescriptions on the risk of epistaxis. A 2000 prospective, cross-sectional, prevalence study showed that individuals affected by epistaxis display significantly higher blood pressure values compared to those without epistaxis ${ }^{(6)}$. It was further found that almost $80 \%$ of people with high blood pressure had sustained arterial hypertension, with approximately $27 \%$ of them being unaware of this major comorbidity. Finally, the number of epistaxis episodes was higher in individuals with sustained arterial hypertension than in those with elevated blood pressure and no sustained arterial hypertension. Two hypotheses may potentially explain the association between epistaxis and hypertension. First, hypertension is known to lead to chronic vascular damage, thus increasing the risk and the severity of bleeding episodes ${ }^{(6,11)}$. In this case, epistaxis would be a consequence of hypertension. That being said, it is also possible that epistaxis, which is defined as a bleeding lesion of the otolaryngological region, triggers the activation of the autonomous nervous system, indirectly leading to hypertension ${ }^{(6,12)}$. In this latter case, epistaxis would be the cause of hypertension. Later, in 2002, Herkner et al. found a positive association between active epistaxis and history of hypertension in 271 emergency department patients with epistaxis and 101 controls $(\mathrm{OR}=2.8,95 \% \mathrm{Cl}: 1.4-5.6)^{(13)}$. In contrast, in a 2003 cross-sectional study comparing 173 patients with a history of epistaxis with 1001 controls, Fuchs and colleagues concluded that hypertension was not associated with a history of epistaxis (in adulthood: $\mathrm{RR}=1.24,95 \% \mathrm{Cl}: 0.83-1.85$; in the previous 6 months: $\mathrm{RR}=0.79$, $95 \% \mathrm{Cl}: 0.40-1.56)^{(14)}$. More recently, Kikidis et al. provided a review of nine studies aiming at the relationship between epistaxis and hypertension ${ }^{(15)}$. Six of the nine included studies found that arterial pressure is higher during an episode of epistaxis. Seven works further assumed a cross-correlation between arterial pressure and the actual incident of epistaxis. Based on 
Table 2. Association between first epistaxis diagnosis and clinical/pharmaceutical variables in patients treated in general practices (logistic regression model).

\begin{tabular}{|c|c|c|c|c|}
\hline Variables ${ }^{1}$ & $\begin{array}{l}\text { Proportion of } \\
\text { epistaxis patients }\end{array}$ & $\begin{array}{l}\text { Proportion of } \\
\text { controls }\end{array}$ & OR $(95 \% \mathrm{CI})^{2}$ & p-value \\
\hline \multicolumn{5}{|l|}{$\begin{array}{l}\text { Diagnoses documented within } 365 \text { days prior to the } \\
\text { index date }\end{array}$} \\
\hline Hypertension (ICD 10: I10) & 59.0 & 49.8 & $1.13(1.08-1.19)$ & $<0.001$ \\
\hline Obesity (ICD 10: E66) & 13.3 & 9.8 & $1.24(1.16-1.33)$ & $<0.001$ \\
\hline Chronic sinusitis (ICD 10: J32) & 13.2 & 12.0 & $1.20(1.13-1.29)$ & $<0.001$ \\
\hline $\begin{array}{l}\text { Other disorders of nose and nasal sinuses including } \\
\text { cyst and mucocele of nose and nasal sinus, deviated } \\
\text { nasal septum, hypertrophy of nasal turbinates, ab- } \\
\text { scess, furuncle and carbuncle of nose (ICD 10: J34) }\end{array}$ & 1.6 & 1.1 & $1.44(1.19-1.74)$ & $<0.001$ \\
\hline Anxiety disorder & 8.5 & 6.2 & $1.23(1.13-1.35)$ & $<0.001$ \\
\hline Adjustment disorder & 11,8 & 9.5 & $1.19(1.11-1.28)$ & $<0.001$ \\
\hline \multicolumn{5}{|l|}{$\begin{array}{l}\text { Drugs prescribed within } 355 \text { days prior to the index } \\
\text { date }\end{array}$} \\
\hline Vitamin $\mathrm{K}$ antagonists (ATC: B01AA) ${ }^{3}$ & 14.2 & 4.1 & $3.55(3.22-3.91)$ & $<0.001$ \\
\hline Heparin group (ATC: B01AB) ${ }^{4}$ & 6.9 & 2.7 & $1.15(1.02-1.29)$ & 0.018 \\
\hline $\begin{array}{l}\text { Platelet aggregation inhibitors excluding heparin } \\
(\text { ATC: } \mathrm{B} 01 \mathrm{AC})^{5}\end{array}$ & 19.2 & 10.2 & $2.02(1.88-2.17)$ & $<0.001$ \\
\hline Direct thrombin inhibitors (ATC: B01AE) ${ }^{6}$ & 0.6 & 0.2 & $2.16(1.47-3.17)$ & $<0.001$ \\
\hline Direct factor Xa inhibitors (ATC: B01AF) ${ }^{7}$ & 4.3 & 1.1 & $3.36(2.85-3.95)$ & $<0.001$ \\
\hline Other antithrombotic agents (ATC: B01AX) ${ }^{8}$ & 0.2 & 0.1 & $1.65(0.84-3.23)$ & 0.148 \\
\hline SSRI (ATC: N06AB) ${ }^{8}$ & 3.3 & 2.0 & $1.26(1.09-1.47)$ & 0.002 \\
\hline Nasal corticosteroids (ATC: R01AD) & 3.6 & 1.7 & $2.24(1.93-2.60)$ & $<0.001$ \\
\hline
\end{tabular}

${ }^{1}$ only variables with $\mathrm{p}<0.05$ are displayed; no significant effect was found for coronary heart disease, diabetes, heart failure, subarachnoid, intracerebral or other non-traumatic intracranial hemorrhage, Osler's disease, allergic rhinitis, nasal polyp, fracture of nasal bones, or depression. ${ }^{2}$ adjusted for diagnoses documented within 365 days prior to the index date. ${ }^{3}$ Vitamin $\mathrm{K}$ antagonists: phenprocoumon and warfarin. ${ }^{4}$ Heparin group: dertoparin, dalteparin, enoxaparin sodium, nadroparin sodium, reviparin, tinzaparin, and heparin. ${ }^{5}$ Platelet aggregation inhibitors: acetylsalicycic acid, clopidogrel, prasugrel, ticagrelor, ticlopidine, and cilostazol. ${ }^{6}$ Direct thrombin inhibitors: dabigatran etexilate. ${ }^{7}$ Direct factor Xa inhibitors: rivaroxaban, apixaban, and edoxaban. ${ }^{8}$ Other antithrombotic agents: danaparoid and fondaparinux sodium.

these previous works, the authors of the review concluded that the presence of hypertension during an actual epistaxis episode cannot establish a causative relationship between hypertension and epistaxis because of confounding stress and possible white coat phenomenon but may lead to the discovery of previously undiagnosed hypertension.

Another finding of the present German study that confirms the importance of hypertension in the physiopathology of epistaxis is the significant impact of obesity on nose bleeds. Nonetheless, as hypertension and obesity were both included as covariables in the multivariate logistic regression model of this work, it is likely that the latter disorder also has its own effect on the risk of epistaxis, with this effect being potentially mediated by other endothelial and vascular dysregulations ${ }^{(16,17)}$.
The same study also found that chronic sinusitis and other disorders of the nose increased the risk of being diagnosed with epistaxis. In 2014, Purkey and colleagues aimed to analyze the seasonal variation of epistaxis incidence in more than 2,400 patients ${ }^{(18)}$, and discovered that epistaxis occurs more frequently during winter and in older patients. It was further found that epistaxis occurrence is positively associated with allergic rhinitis, chronic sinusitis, coagulopathy, hereditary hemorrhagic telangiectasia, hematologic malignancy, and hypertension. These local disorders of the otolaryngological region, in particular sinusitis, are associated with an overactivation of the inflammatory system ${ }^{(19)}$, which could result in an increased number of bleeding episodes such as epistaxis.

Of particular interest was the impact of anxiety and adjustment 
disorder on epistaxis, which, to our knowledge, has not been previously described in the literature ${ }^{(20)}$. In 2005, Cheung et al. estimated in 197 patients that hypertension was associated with anxiety but not depression ${ }^{(21)}$. More recently, a 2013 UK study showed in a cohort of late middle-aged men and women that symptoms of depression and anxiety are associated with a diagnosis of hypertension five years later ${ }^{(22)}$. Although these findings must be interpreted with caution, the effect of these psychiatric disorders on epistaxis may be secondary to the increase of systolic and diastolic blood pressures. Nevertheless, some researchers have also suggested that families of molecules prescribed for the treatment of depression and anxiety are associated with bleeding episodes ${ }^{(23,24)}$. A 2004 work based on data collected from 1992 through 2000 discovered a significant association between the use of serotonin reuptake inhibitors and the risk of hospital admission for abnormal bleeding ( $O R=1.9$, 95\% Cl: 1.1-3.5) ${ }^{(23)}$. Another study, which was published in 2011 and included 100 individuals, suggested that the prescription of SSRIs with warfarin increased the risk of any bleeding event ${ }^{(24)}$.

These results were later corroborated by Cheng et al., who found an increased risk of upper and lower gastrointestinal bleeding in 9,753 SSRI users in a 10-year follow-up study (hazard ratios equal to 1.97 and 2.96, respectively) ${ }^{(25)}$. Finally, Renoux and colleagues examined 1,363,990 users of SSRI from over 650 general practices in the UK in a population-based cohort study ${ }^{(26)}$. They found an increased risk of intracranial hemorrhage in people taking SSRIs when compared to people taking tricyclic antidepressants $(\mathrm{RR}=1.17)$, with this risk being the highest during the first 30 days of treatment. The authors further showed an increased risk in patients receiving strong SSRIs when compared to patients receiving weak SSRIs ( $R R=1.25$ ). Finally, it was estimated that concomitant use of oral anticoagulants substantially increased the risk of intracranial hemorrhage ( $R R=1.73)$. The association between the use of SSRIs and epistaxis, and bleeding in general, has been explained by the fact that SSRIs block platelet serotonin reuptake, leading to a serotonin deficiency in platelets and aggregation impairment ${ }^{(27,28)}$.

This German study showed that the risk of epistaxis was increased when anticoagulants, platelet inhibitors or nasal corticosteroids were prescribed. In 2008, Benninger discovered in 559 consecutive patients that the incidence of epistaxis was around $5 \%$ within two months after initiating intranasal steroid therapy, underlying the idea that such drugs may tend to damage blood vessels ${ }^{(29)}$. The negative impact of such drugs on bleeding was later corroborated in another clinical context, as corticosteroids were associated with an increased risk of gastrointestinal bleeding ${ }^{\left({ }^{30}\right)}$. In 2011, Jura-Szołtys and Chudek found in people undergoing percutaneous coronary angioplasty with stent implantation that epistaxis occurred in more than $6 \%$ of the population ${ }^{(31)}$. The incidence of epistaxis was similar between individuals receiving clopidogrel, ASA, or both clopidogrel and
ASA. Interestingly, the authors estimated that approximately one patient with epistaxis out of five disrupted his or her platelet inhibition treatment. Finally, hypertension, chronic kidney disease, and liver cirrhosis were risk factors for the occurrence of this complication. Later, in 2016, Stadler et al. showed in 603 emergency epistaxis patients that recurrences are more frequent when individuals are exposed to vitamin $\mathrm{K}$ antagonists (32). It was discovered in the same analysis that the exposure to ASA increases the severity of epistaxis recurrences and the need for invasive treatments. In line with these two works, platelet inhibitors and anticoagulants, in particular vitamin $\mathrm{K}$ antagonists, were found to be associated with an increase in the risk of being diagnosed with epistaxis.

Finally, large database studies have been performed regarding the risk of major bleeding in patients treated with oral anticoagulants. In a 2016 Danish nationwide cohort study including 61,678 patients, Larsen et al. found that apixaban (Eliquis) and dabigatran (Pradaxa) have a lower risk of death, major bleeding, or any bleeding than warfarin ${ }^{(33)}$. One year later, Hohnloser and colleagues found in 35,013 patients from Germany that apixaban has a reduced bleeding risk compared to phenprocoumon, whereas dabigatran has a bleeding risk similar to that of phenprocoumon, and rivaroxaban has a higher bleeding risk than phenprocoumon ${ }^{(34)}$. While these two studies are of particular importance, no data is yet available on the impact of the use of such oral anticoagulants on the risk of epistaxis.

This study was subject to several limitations. First, this retrospective work only enabled the analysis of associations and prevalence estimations, not causal relationships. Second, the diagnosis of epistaxis and other conditions relied solely on ICD codes. Moreover, the database contained no information on the severity of epistaxis. Furthermore, there was no information on socioeconomic status, and information on lifestyle-related risk factors was also unavailable. Finally, no detailed documentation about therapy side effects was available so the associations between therapy and epistaxis could only be estimated. One strength of the study is the large nationwide database. Another strength is the use of real-world data on diagnoses in primary care practices where diagnoses are continuously documented, allowing unbiased exposure assessment (no recall bias).

\section{Conclusion}

Overall, we found the occurrence of epistaxis to be associated with multiple medical and psychiatric disorders. The intake of platelet inhibitors, anticoagulants, and nasal corticosteroids is also associated with this risk.

\section{Acknowledgements}

Professional English language editing services were provided by Claudia Jones, MA, Radford, VA, United States. 


\section{Authorship contribution}

DUS contributed to the analysis and interpretation of the data, drafted the manuscript and gave the final approval of the version to be published. LJ, and AMS contributed substantially to the design, analysis and interpretation of the data, drafted the manuscript, and gave the final approval of the version to be published. KK contributed substantially to the conception, design, and interpretation of the data, revised the manuscript critically for important content and gave the final approval of the version to be published.

\section{Conflict of interest}

None.

\section{References}

1. Abrich V, Brozek A, Boyle TR, Chyou P-H, Yale $\mathrm{SH}$. Risk Factors for Recurrent Spontaneous Epistaxis. Mayo Clin Proc. 2014 décembre;89(12):1636-43.

2. Pallin DJ, Chng Y-M, McKay MP, Emond JA, Pelletier AJ, Camargo CA. Epidemiology of epistaxis in US emergency departments, 1992 to 2001. Ann Emerg Med. 2005 Jul;46(1):77-81

3. Ingrand I, Ingrand P, Gilbert-Dussardier B Defossez G, Jouhet V, Migeot $V$, et al. Altered quality of life in Rendu-Osler-Weber disease related to recurrent epistaxis. Rhinology. 2011 Jun;49(2):155-62.

4. Fokkens WJ. Epistaxis management: evaluation of old tricks and new treatment options. Rhinology. 2011 Oct;49(4):385-6.

5. Goljo E, Dang R, lloreta AM, Govindaraj S. Cost of management in epistaxis admission: Impact of patient and hospital characteristics. The Laryngoscope. 2015 Dec;125(12):2642-7.

6. Herkner $H$, Laggner AN, Müllner $M$, Formanek M, Bur A, Gamper G, et al. Hypertension in patients presenting with epistaxis. Ann Emerg Med. 2000 Feb;35(2):126-30.

7. Knopfholz J, Lima-Junior E, Précoma-Neto D, Faria-Neto JR. Association between epistaxis and hypertension: a one year follow-up after an index episode of nose bleeding in hypertensive patients. Int J Cardiol. 2009 May 29;134(3):e107-9.

8. Soyka MB, Rufibach K, Huber A, Holzmann D. Is severe epistaxis associated with acetylsalicylic acid intake? The Laryngoscope. 2010 Jan;120(1):200-7.

9. Stadler RR, Kindler R, Holzmann D, Soyka $M B$. The long-term fate of epistaxis patients with exposure to antithrombotic medication. Eur Arch Oto-Rhino-Laryngol Off J Eur Fed Oto-Rhino-Laryngol Soc EUFOS Affil Ger Soc Oto-Rhino-Laryngol - Head Neck Surg. 2016 Sep;273(9):2561-7

10. Becher H, Kostev K, Schröder-Bernhardi D. Validity and representativeness of the "Disease Analyzer" patient database for use in pharmacoepidemiological and pharmacoeconomic studies. Int J Clin Pharmacol Ther. 2009 Oct;47(10):617-26.

11. Ibrashi F, Sabri N, Eldawi M, Belal A. Effect of atherosclerosis and hypertension on arterial epistaxis. J Laryngol Otol. 1978 Oct;92(10):877-81.

12. Randall DA, Freeman SB. Management of anterior and posterior epistaxis. Am Fam Physician. 1991 Jun;43(6):2007-14.

13. Herkner H, Havel C, Müllner M, Gamper G, Bur A, Temmel AF, et al. Active epistaxis at ED presentation is associated with arterial hypertension. Am J Emerg Med. 2002 Mar;20(2):92-5.

14. Fuchs FD, Moreira LB, Pires CP, Torres FS, Furtado MV, Moraes RS, et al. Absence of association between hypertension and epistaxis: a population-based study. Blood Press. 2003;12(3):145-8.

15. Kikidis D, Tsioufis K, Papanikolaou V, Zerva K, Hantzakos A. Is epistaxis associated with arterial hypertension? A systematic review of the literature. Eur Arch Oto-Rhino-Laryngol Off J Eur Fed OtoRhino-Laryngol Soc EUFOS Affil Ger Soc Oto-Rhino-Laryngol - Head Neck Surg. 2014 Feb;271(2):237-43.

16. Fantin F, Di Francesco V, Rossi A, Giuliano K, Marino F, Cazzadori M, et al. Abdominal obesity and subclinical vascular damage in the elderly. J Hypertens. 2010 Feb;28(2):333-9.

17. Iantorno M, Campia U, Di Daniele N, Nistico S, Forleo GB, Cardillo C, et al. Obesity, inflammation and endothelial dysfunction. J Biol Regul Homeost Agents. 2014 Jun;28(2):169-76.

18. Purkey MR, Seeskin Z, Chandra R. Seasonal variation and predictors of epistaxis. The Laryngoscope. 2014 Sep;124(9):2028-33.

19. Lee S, Lane AP. Chronic Rhinosinusitis as a Multifactorial Inflammatory Disorder. Curr Infect Dis Rep. 2011 Apr;13(2):159-68.

20. Choudhury N, Sharp HR, Mir N, Salama NY. Epistaxis and oral anticoagulant therapy. Rhinology. 2004 Jun;42(2):92-7.

21. Cheung BM, Au T, Chan S, Lam C, Lau S, Lee $R$, et al. The relationship between hypertension and anxiety or depression in Hong Kong Chinese. Exp Clin Cardiol. 2005;10(1):21-4.

22. Ginty AT, Carroll D, Roseboom TJ, Phillips $A C$, de Rooij SR. Depression and anxiety are associated with a diagnosis of hypertension 5 years later in a cohort of late middle-aged men and women. J Hum Hypertens. 2013 Mar;27(3):187-90.

23. Meijer WEE, Heerdink ER, Nolen WA Herings RMC, Leufkens HGM, Egberts ACG. Association of risk of abnormal bleeding with degree of serotonin reuptake inhibition by antidepressants. Arch Intern Med. 2004 Nov 22;164(21):2367-70.
24. Cochran KA, Cavallari LH, Shapiro NL, Bishop JR. Bleeding Incidence with Concomitant Use of Antidepressants and Warfarin. Ther Drug Monit. 2011 Aug;33(4):433-8.

25. Cheng $Y-L, H u H-Y$, Lin $X-H$, Luo J-C, Peng $Y-L$, Hou $M-C$, et al. Use of SSRI, But Not SNRI, Increased Upper and Lower Gastrointestinal Bleeding: A Nationwide Population-Based Cohort Study in Taiwan. Medicine (Baltimore). 2015 Nov;94(46):e2022.

26. Renoux C, Vahey S, Dell'Aniello S, Boivin J-F. Association of Selective Serotonin Reuptake Inhibitors With the Risk for Spontaneous Intracranial Hemorrhage. JAMA Neurol. 2017 Feb 1;74(2):173-80.

27. Silverstein MG, El-Amin CK, Shively CA Selective Serotonin Reuptake Inhibitor and Bleeding in a Cynomolgus Macaque (Macaca fascicularis). Comp Med. 2014 Jun;64(3):221-3.

28. Bakish D, Cavazzoni P, Chudzik J, Ravindran A, Hrdina PD. Effects of selective serotonin reuptake inhibitors on platelet serotonin parameters in major depressive disorder Biol Psychiatry. 1997 Jan 15:41(2):184-90.

29. Benninger MS. Epistaxis and its relationship to handedness with use of intranasal steroid spray. Ear Nose Throat J. 2008 Aug;87(8):463-5.

30. Narum S, Westergren T, Klemp M Corticosteroids and risk of gastrointestinal bleeding: a systematic review and meta-analysis. BMJ Open. 2014 May 1;4(5):e004587.

31. Jura-Szołtys E, Chudek J. Epistaxis as the reason for premature discontinuation of clopidogrel after percutaneous coronary angioplasty with stent implantation. Kardiol Pol. 2011;69(8):817-23.

32. Stadler RR, Kindler R, Holzmann D, Soyka $M B$. The long-term fate of epistaxis patients with exposure to antithrombotic medication. Eur Arch Oto-Rhino-Laryngol Off J Eur Fed Oto-Rhino-Laryngol Soc EUFOS Affil Ger Soc Oto-Rhino-Laryngol - Head Neck Surg. 2016 Sep;273(9):2561-7.

33. Larsen TB, Skjøth F, Nielsen PB, Kjældgaard JN, Lip GYH. Comparative effectiveness and safety of non-vitamin $\mathrm{K}$ antagonist oral anticoagulants and warfarin in patients with atrial fibrillation: propensity weighted nationwide cohort study. BMJ. 2016 Jun 16:353:i3189.

34. Hohnloser SH, Basic E, Nabauer M Comparative risk of major bleeding with 
new oral anticoagulants (NOACs) and phenprocoumon in patients with atrial fibrillation: a post-marketing surveillance study. Clin Res Cardiol Off J Ger Card Soc 2017 Mar 14

Prof. Dr. rer. med. Karel Kostev Epidemiology

QuintilesIMS

Darmstädter Landstraße 108

60598 Frankfurt am Main

Germany

Tel: +49-(0)69-66 04-4878

E-mail:kkostev@de.imshealth.com 